\title{
ЗАПИСЬ СТРУКТУРЫ ВОЛНОВОГО ФРОНТА ПИКОСЕКУНДНОГО СИГНАЛА ПРИ ПОМОЩИ ФОТОХИМИЧЕСКИ АККУМУЛИРОВАННОГО СТИМУЛИРОВАННОГО СВЕТОВОГО ЭХА
}

A. REBANE, R. KAARLI, P. SAARI. PIKOSEKUNDILISE SIGNAALI LAINEFRONDI STRUKTUURI REGISTREERIMINE FOTOKEEMILISELT AKUMULEERITUD STIMULEERITUD FOOTONKAJA ABIL

A. REBANE, R. KAARLI, P. SAARI. RECORDING OF PICOSECOND WAVEFRONTS BY PHOTOCHEMICALLY ACCUMULATED STIMULATED PHOTON ECHO

\author{
(Представил К. К. Ребане)
}

Метод фотохимнчески аккумулированного стимулированного светового эха (ФАССЭ) является перспективным как для исследования быстропротекающих процессов фазовой релаксации в низкотемпературных примесных средах, так и для голографической записи пространственновременных характеристик импульсных световых полей $\left[{ }^{1-3}\right]$.

Этот метод основан, с одной стороны, на импульсном возбуждении в среде когерентных запаздывающих откликов типа светово эха, с другой стороны, на эффекте фотохимического выжигания провалов (ФВП) $\left[{ }^{4,5}\right]$ - просветлении поглощающей среды в узких спектральных интервалах под действием узкополосного лазерного излучения, позволяющим с очень высокой спектральной селективностью записывать информацию. По сравнению с другими известными методами эхо-голографии $\left[{ }^{6,7}\right]$, запись ФАССӘ-голограмм имеет важную особенность: благодаря долгому времени жизни фотохимических провалов информация о пространственно-спектральном распределении интенсивности светового поля может сохраняться в голограмме в течение многих часов и дней, т. е. на многие порядки величины дольше времени жизни обычных эхо-голограмм, разрушающихся со временем релаксации возбужденных электронных состояний молекул.

Недавно были выполнены эксперименты, где при помощи ФАССЭ была осуществлена голографическая запись временной структуры пикосекундного импульсного сигнала $\left[{ }^{8,9}\right]$, а также некоторых пространственных характеристик пикосекундных импульсов. В данной работе описываются детальная запись и воспроизведение пространственной структуры пикосекундного сигнала, а также сообщается о наблюдении сопряженного сигнала с обращенным волновым фронтом.

Голограммы записывались в области максимума полосы поглощения молекул октаэтилпорфирина в полистироловой матрице на длине волны 617 нм. Образец светочувствительной среды погружался в оптический гелиевый криостат со сквозными окнами, где он охлаждался до температуры 1,8 К. Для записи и считывания голограмм применялся квазинепрерывный (82 МГц) пикосекундный лазер на красителе родамин $6 Ж$, который синхронно накачивался аргоновым ионным лазером. Длительность импульсов от пикосекундного лазера составляла 2 пс, 


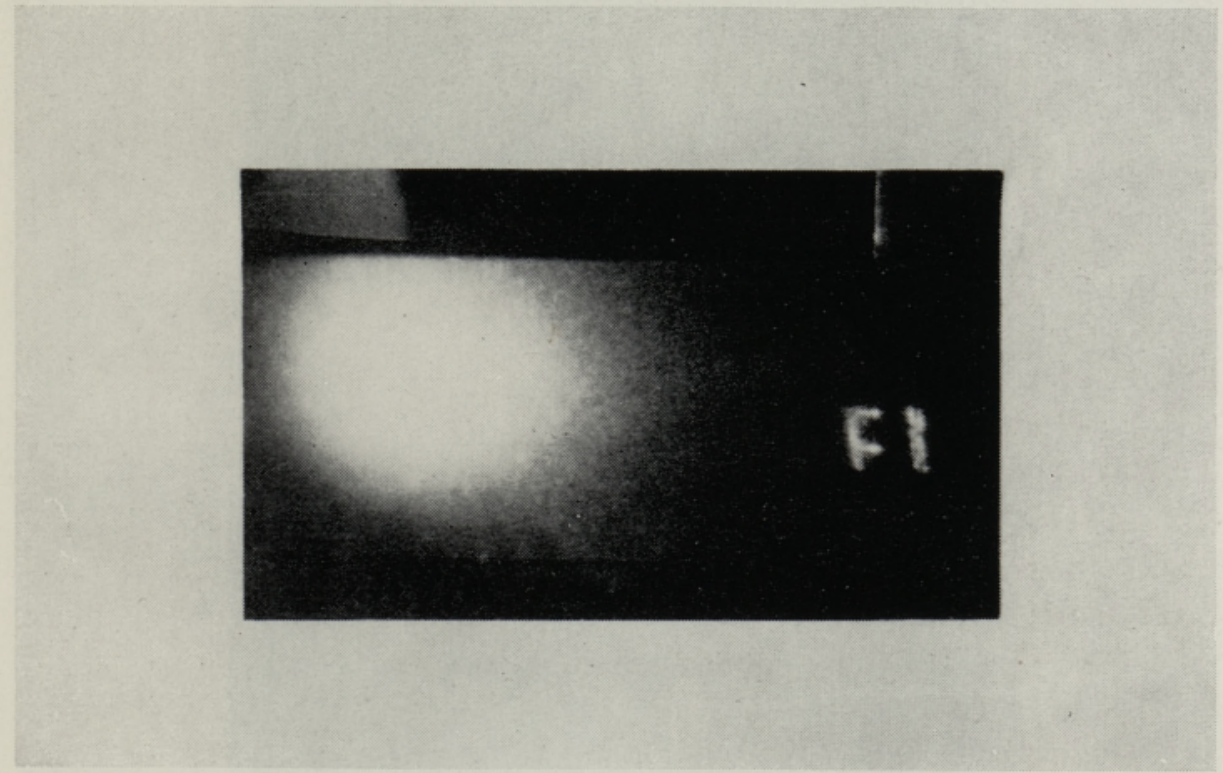

Рис. 1. Изображение справа - воспроизведенный сигнал с плоским волновым фронтом в виде двух букв. Длительнссть сигнала 2 пс, задержка относительно считывающих импульсов 10 пс. Слева - рассеянный на экране воспроизводящий пучок пикосекундных импульсов. 


\section{A *}
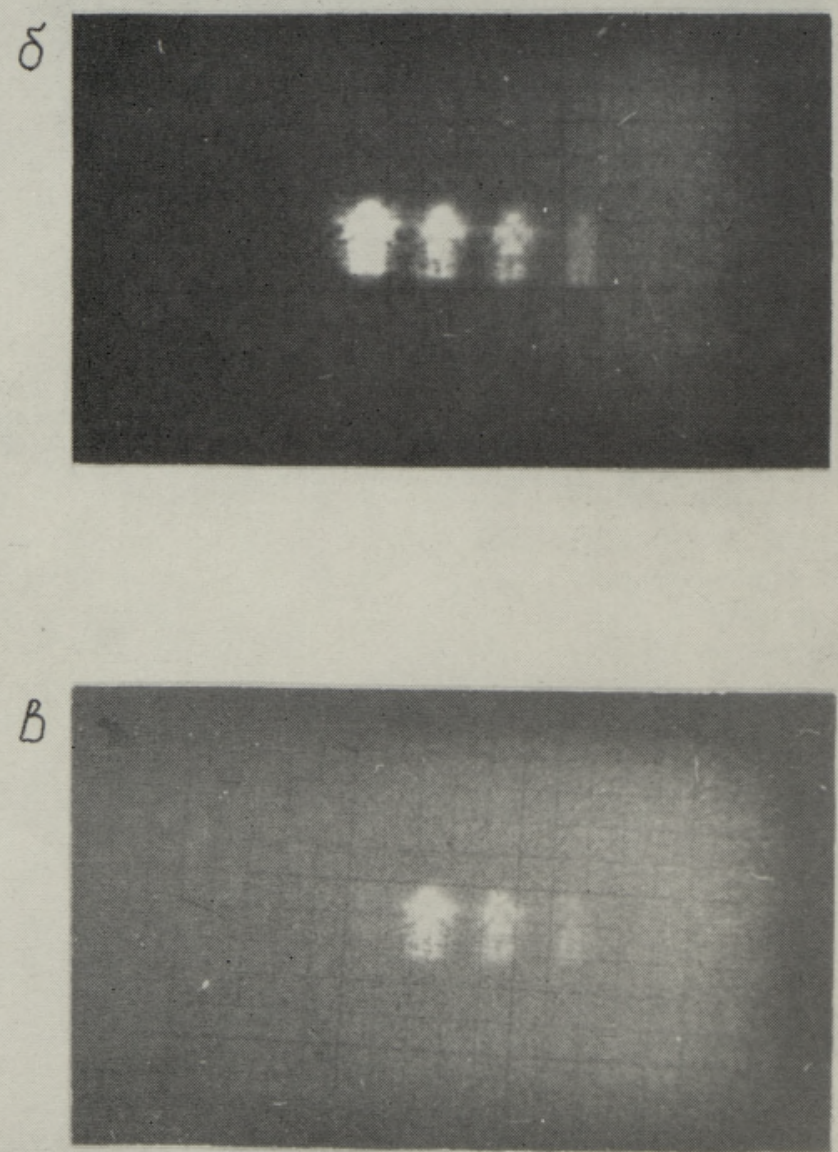

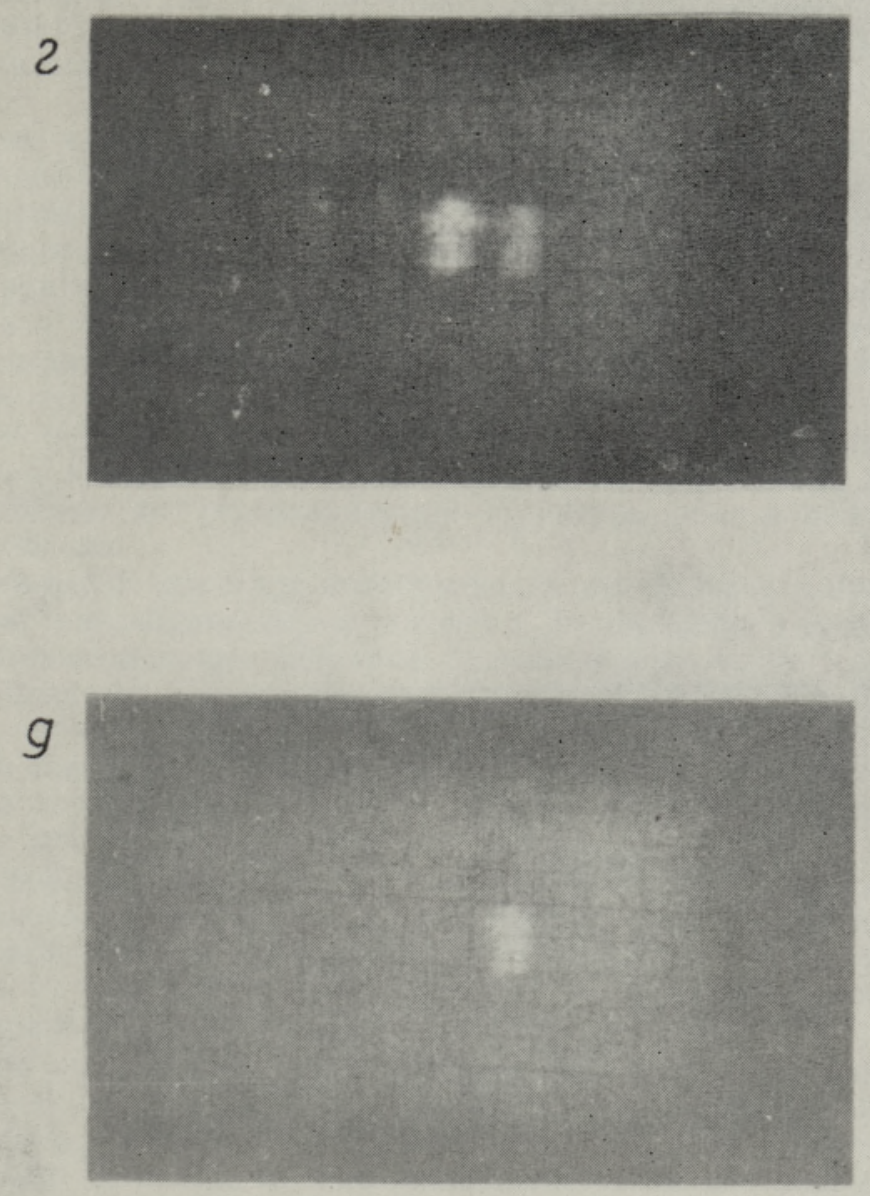

Рис. 2. а - изображение записываемого сигнала со сходящимся волновым фронтом. Временная задержка второй, третьей и четвертой стрелки относительно первой стрелки слева составляет 50, 100 и 150 пс;

6 - воспроизведенное прямое изображение четырех стрелок в случае, когда опорный импульс опережал на 50 пс всю последовательность сигнальных импульсов; $8,2, \partial-$ воспроизведенные прямые изображения сигнала в случаях, когда опорный импульс подавался соответственно в момент между первым и вторым (в), вторым и третьим (2) и третьим и четвертым ( $\partial)$ сигнальными импульсами. На экране за криостатом вопроизводятся соответственно три, две или одна стрелки. 


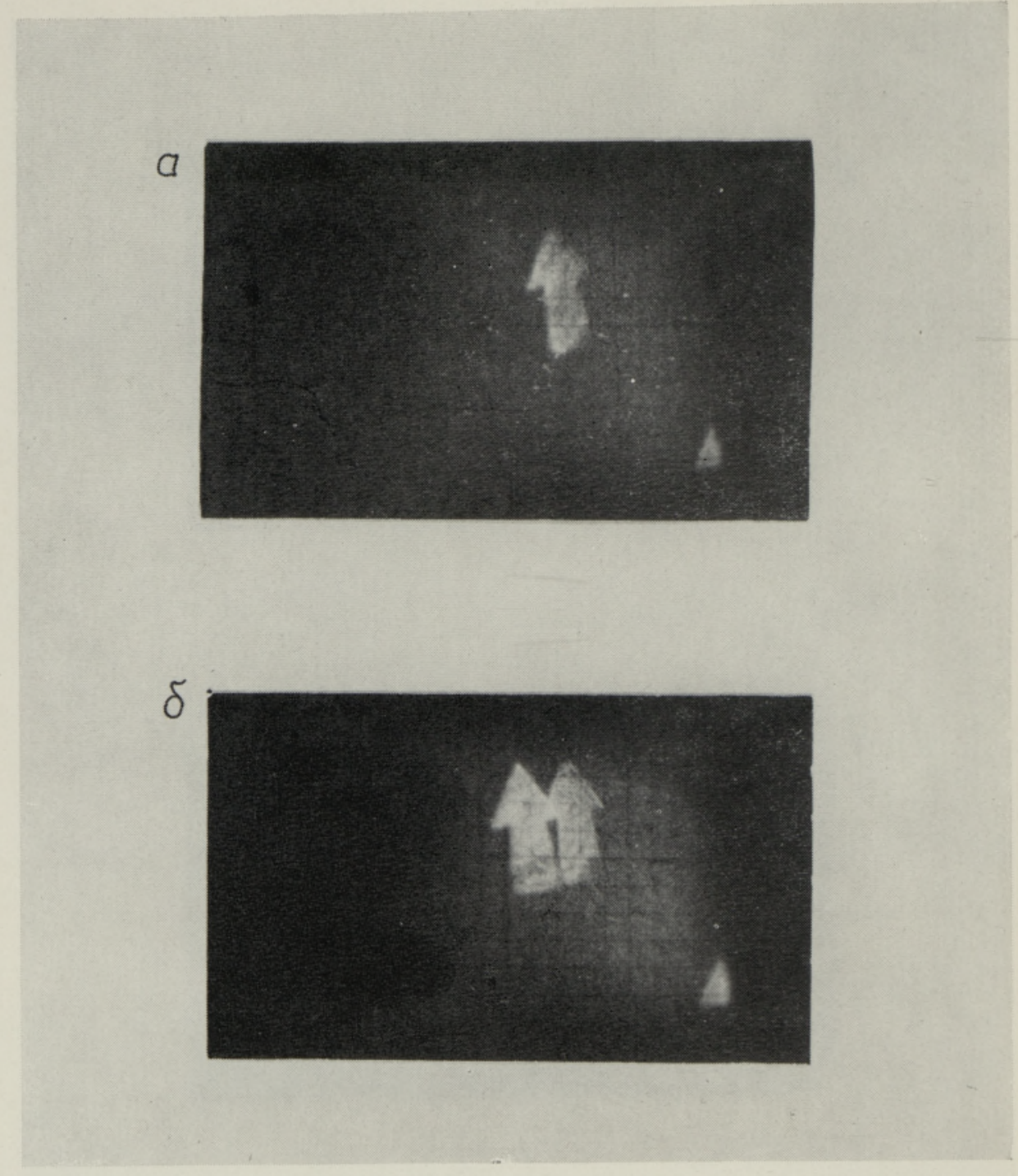

Рис. 3. Изображения сопряженного сигнала на экране перед криостатом. а - сопряженный сигнал в случае подачи опорного импульса в момент между первой и второй стрелкой сигнала;

6 - две стрелки в сопряженном сигнале в случае подачи опорного импульса в момент между второй и третьей стрелкой сигнала. Отмечаются увеличение изображения стрелок из-за расходящегося характера волнового фронта сопряженной волны, а также отсутствие дифракционной структуры в изображении. 
ширина спектра́ импульсов была $6 \mathrm{~cm}^{-1}$, чӓстота повторенния импулйьсов при средней выходной мощности лазера 100 мВт составляла 82 МГц.

Запись и считывание голограмм осуществлялись следующим образом: пучок от пикосекундного лазера расширялся в телескопе до поперечного размера 5 см и далее разделялся на опорный и сигнальный пучки. Оба пучка при помощи системы призм и зеркал направлялись на расположенный в криостате образец, где они пересекались под углом $6^{\circ}$.

На входе в криостат опорный пучок имел плоский волновой фронт и обладал средней по времени интенсивностью $0,5 \mathrm{m \kappa}_{\mathrm{K}} \mathrm{c}_{\mathrm{c}}{ }^{-2}$. Волновой фронт сигнального пучка модифицировался вставлением транспарантов, линзы и эталона Фабри-Перо и обладал сложной пространственно-временной структурой. Средняя интенсивность сигнального пучка была в два-три раза ниже интенсивности опорного пучка. Относительная задержка между опорным и сигнальными импульсами изменялась передвижением одной из отражающих призм в опорном канале в пределах \pm 300 пс от переднего фронта сигнала. Отсутствие перекрытия во времени сигнала и опорного импульса проверялось при помощи микроскопа по исчезновению интерференционной структуры поля в области расположения образца.

Максимальный контраст воспроизводимого сигнала достигался при экспознциях в несколько десятков секунд. За это время в среде накапливалось фотовыжигающее действие большого количества $\left(\sim 10^{10}\right)$ одинаковых последовательностей опорного и сигнального импульсов, следующих с частотой 82 МГц повторения пикосекундного лазера. После экспозиции сигнальный канал перекрывался экраном, а в качестве считывающего пучка использовался либо ослабленный нейтральными фильтрами луч опорного канала, либо параллельный пучок, направленный противоположно опорному лучу. Воспроизведенные изображения фотографировались на удалении 20 см от выходных окон криостата с экранов, расположенных соответственно для прямого и обратного считывающих пучков с задней и с передней стороны криостата относительно направления записывающих пучков.

В первой части эксперимента в сигнальный пучок вставлялся транспарант в виде двух букв высотой 5 мм. Таким образом, сигнал имел вид одного пикосекундного импульса длительностью 2 пс с примерно плоским волновым фронтом, но с модулированным по сечению распределением интенсивности. Задержка сигнального импульса относительно опорного импульса составляла при записи 10 пс.

На рис. 1 приведено воспроизведенное с голограммы прямое изображение записанного сигнала. Следует подчеркнуть, что воспроизведенный сигнал запаздывал относительно считывающих импульсов точно на время задержки между выжигающими импульсами, т. е. на 10 пс.

Во второй части экспериментов сигнальный пучок пропускался через транспарант в виде одной стрелки и перед фокусирующей линзой с фокусным расстоянием 2 м и далее проходил через эталон Фабри-Перо толщиной 4,5 мм, расположенный под углом $45^{\circ}$ относительно оси сигнального пучка. В результате сигнальный пучок имел на образце вид четырех расположенных рядом стрелок, интенсивность которых убывала в порядке возрастания числа отражений в эталоне Фабри-Перо (рис. 2,a). Относительный сдвиг стрелок во времени был равен двойному времени прохождения света через эталон и составлял 50 пс. Передвижением оптической линии задержки момент подачи опорного импульса выбирался либо с опережением первого сигнального импульса, либо в промежутках между последующими импульсами таким образом, что импульсы во времени не перекрывались.

После экспозиции на экране за криостатом наблюдалось воспроиз- 
веденное прямое изображение сигнала (рис. 2), а на экране, распіоложенном перед криостатом, - сопряженное изображение (рис. 3). Как и следовало ожидать, в соответствии с рассмотренными в $\left[{ }^{9,10}\right]$ особенностями причинного действия ФАССЭ-голограмм, вклад в прямое изображение вносила лишь та часть сигнала, которая подавалась на голограмму после опорного импульса. Опережающая опорный импульс часть сигнала вносила вклад в сопряженное изображение, которое наблюдалось при обратном направлении считывающего импульса. Кроме того, поскольку прямой сигнал имел сходящийся волновой фронт, а сопряженный расходящийся, то это приводило к увеличенному изображению транспаранта на экране. Следует подчеркнуть, что в сопряженном сигнале порядок воспроизведенных импульсов был обращен во времени, т. е. имело место пространственно-временное обращение волнового фронта сигнала.

Авторы признательны К. К. Ребане за обсуждение, Н. С. Шелехову и О. В. Бандюку за изготовление образцов оптического качества.

\section{ЛИТЕРА Т У РА}

1. Ребане А. К., Каарли Р. К., Саари П. М. Опт. и спектр., 55, № 3, 405-407 (1983).

2. Ребане А. К., Каарли Р. К., Саари П. М. Письма в ЖЭТФ, 38, вып. 7, 320-323 (1983).

3. Rebane, A., Kaarli, R., Saari, P., Anijalg, A., Timpmann, K. Opt. Commun., 47, № 3, 173-176 (1983).

4. Гороховский А. А., Каарли Р. К., Ребане А. К. Письма в ЖЭТФ, 20, вып. 7, 474479 (1974) 5. Kharlamov, B. M., Personov, R. I., Bykovskaya, L. A., Opt. Commun., 12, № 12,
191-193 (1974).

6. Shtyrkov, E. I., Samartsev, V. V., Phys. status solidi (a), 45, 647-655 (1978).

7. Carlson, N. W., Babbitt, W. R., Mossberg, T. W. Opt. Lett., 8, 623-625 (1983).

8. Rebane, A., Kaarli, R. Chem. Phys. Lett., 101, № 3, 317-319 (1983).

9. Саари П. М., Каарли Р. К., Ребане А. К. Квант. электроника, 12, № 4, 672-682, (1985)

10. Саари П. М., Ребане А. К. Изв. АН ЭССР. Физ., Матем., 33, № 3, 322-332, (1984).

Ннститут физики

Академии наук Эстонской ССР
Поступила в редакцию $6 /$ VI 1985 